\title{
O PROCESSO DE ENFERMAGEM EM UMA UNIDADE DE QUEIMADOS: UM ESTUDO ETNOGRÁFICO
}

\author{
Lidia Aparecida Rossi ${ }^{1}$ \\ Lisete Diniz Ribas Casagrande ${ }^{2}$
}

Rossi LA, Casagrande LDR. O processo de enfermagem em uma unidade de queimados: um estudo etnográfico. Rev Latino-am Enfermagem 2001 setembrooutubro; 9(5):39-46.

Os objetivos deste estudo etnográfico foram compreender o significado cultural que os profissionais que atuam em uma Unidade de Queimados atribuem ao processo de enfermagem e identificar os fatores que interferem na implementação dessa metodologia de assistência. Os dados foram coletados através de observações participantes e entrevistas semi-estruradas. Os resultados indicam que os profissionais de enfermagem dessa Unidade compreendem o processo de enfermagem como uma atividade burocrática. Alguns fatores determinam essa percepção: a forma como o processo de enfermagemé ensinado e interpretado, a condução do trabalho com base em rotinas, os saberes e os poderes no mundo da vida dessa Unidade.

PALAVRAS CHAVE: processos de enfermagem, etnografia, planejamento de assistência ao paciente

\section{THE NURSING PROCESS IN A BURNS UNIT: AN ETHNOGRAPHIC STUDY}

This ethnographic study aimed at understanding the cultural meaning that nursing professionals working at a Burns Unit attribute to the nursing process as well as at identifying the factors affecting the implementation of this methodology. Data were collected through participant observation and semi-structured interviews. The findings indicate that, to the nurses from the investigated unit, the nursing process seems to be identified as bureaucratic management. Some factors determining this perception are: the way in which the nursing process has been taught and interpreted, routine as a guideline for nursing activity, and knowledge and power in the life-world of the Burns Unit.

KEY WORDS: nursing process, ethnography, patient care planning

\section{EL PROCESO DE ENFERMERÍA EN UNA UNIDAD DE QUEMADOS: UN ESTUDIO ETNOGRÁFICO}

Los objetivos de este estudio etnográfico fueron: comprender el significado cultural que los profesionales que atuan en una Unidad de Quemados atribuyen al proceso de enfermería e identificar los factores que interfieren en la implementación de esa metodologia de atención. Los datos fueron recolectados a través de observaciones participantes y entrevistas semi-estructuradas. Los resultados indican que los profesionales de enfermería de esa Unidad comprenden el proceso de enfermería como una actividad burocrática. Algunos factores determinan esa percepción: la forma como el proceso de enfermería es enseñado, la conducción del trabajo basado en rutinas, los saberes y poderes en el mundo de la vida de esa Unidad.

PALABRAS CLAVES: proceso de enfermería, etnografía, planificación de la atención al paciente

\footnotetext{
${ }^{1}$ Professor Doutor da Escola de Enfermagem de Ribeirão Preto da Universidade de São Paulo, Centro Colaborador da OMS para o desenvolvimento da pesquisa em enfermagem, e-mail: rizzardo@eerp.usp.br, ${ }^{2}$ Professor Doutor da Faculdade de Filosofia Ciências e Letras de Ribeirão Preto da Universidade de São Paulo
} 


\section{INTRODUÇÃO}

$D_{\text {esde a década de } 70 \text {, quando o processo de enfermagem }}$ surgiu como uma forma de organização dos cuidados de enfermagem e como uma alternativa para o alcance do status profissional do enfermeiro, muitos enfermeiros têm tentado operacionalizar essa metodologia de assistência no Brasil. Com a aprovação da Lei do Exercício Profissional de Enfermagem ${ }^{(1)}$, que estabeleceu como atribuição privativa do enfermeiro a prescrição de enfermagem ${ }^{(2)}$, esse fato pode ser observado na literatura nacional na década de 80 , mediante os vários relatos sobre experiências de implantação do processo de enfermagem em instituições de saúde brasileiras $^{(3-4)}$. Nesse mesmo período, vários autores destacam alguns fatores que interferem na implementação dessa metodologia de assistência como por exemplo a falta de consenso entre os docentes sobre a sua utilização, como uma premissa básica no contexto da assistência ao ser humano, as divergências, quanto à forma de operacionalização, entre aqueles que a utilizam ${ }^{(5)}$ e a questão da falta de motivação para a mudança, por parte dos enfermeiros ${ }^{(6)}$.

$O$ processo de enfermagem é entendido como uma atividade deliberada, lógica e racional, através da qual a prática de enfermagem é desempenhada sistematicamente e que compreende cinco componentes inter-relacionados: coleta de dados, diagnóstico, planejamento, implementação e avaliação $0^{(7)}$.

É importante considerar que essa metodologia de assistência, além do método, envolve uma abordagem para o cuidado que pressupõe o cuidado individualizado. Assim, o processo de enfermagem oferece para o enfermeiro a possibilidade de organizar o seu trabalho com base em crenças, valores e em um método ${ }^{(8)}$. Embora o processo de enfermagem pressuponha o cuidado individualizado, não podemos afirmar que a implementação dessa metodologia garanta a realização do cuidado. O processo de enfermagem é entendido como umaalternativa para que os enfermeiros alcancem um status profissional mediante a realização de uma prática científica; entretanto, muitas vezes, é incorporado de forma ritualizada, como se fosse um messias que, se seguirmos, estaremos salvos ${ }^{(8)}$.

Encontramos na revisão de literatura, artigos que abordaram as atitudes de enfermeiros frenteà utilização dessa metodologia de assistência ${ }^{(9)}$, que analisaram o contexto sociológico em que o processo de enfermagem emergiu e a utilização sua na prática clínica ${ }^{(10)}$ e que realizaram uma crítica aos conceitos e as expectativas da profissão relacionadas à implementação dessa metodologia de assistência ${ }^{(11)}$. Alguns estudos buscaram compreender a perspectiva cultural dos enfermeiros sobre aspectos específicos que envolvem a utilização do processo de enfermagem, como a questão da documentação ${ }^{(12)} \mathrm{e}$ a relação entre processo de enfermagem e cuidado individualizado ${ }^{(13)}$

No Brasil, a partir do final da década de 80 , observa-se maior ênfase nos estudos sobre os diagnósticos de enfermagem ${ }^{(14-15)}$ e a partir de então, um enfoque no processo de raciocínio diagnóstico ${ }^{(16)}$. Entretanto, não encontramos, na literatura, estudos etnográficos que enfocassem os significados culturais atribuídos a essa metodologia pelos profissionais de enfermagem, foco de interesse dessa investigação.

A operacionalização do processo de enfermagem e a individualização do cuidado implicam na adoção, pelo enfermeiro, de um conjunto de crenças e valores que valorizam o ser humano e o consideram como cidadão, mas que nem sempre fazem parte do dia a dia da prática nas instituições de saúde no Brasil. Na prática hospitalar, os enfermeiros têm se deparado com políticas estabelecidas por outros profissionais, que não estimulame, muitas vezes, limitam o espaço de criatividade dos enfermeiros.

Os enfermeiros da Unidade de Queimados (UQ) do Hospital das Clínicas da Faculdade de Medicina de Ribeirão Preto (HCFMRP), onde este estudo foi desenvolvido, têm tentado utilizar o processo de enfermagem na organização da assistência ao paciente que sofreu queimaduras, desde a sua ativação, em 1982. Em todas as tentativas realizadas, a prescrição de enfermagem sempre foi registrada; as demais etapas, muitas vezes, não eram documentadas. Em 1991, foi desenvolvido, em conjunto com os enfermeiros desta Unidade, um plano de atividade educativa, que teve como objetivos: "analisar e reformular a prática do processo de enfermagem nessa Unidade $^{\text {(17) }}$. Esse trabalho resultou na implementação do processo de enfermagem nessa Unidade, mediante uma adaptação na fase diagnóstica da Taxionomia I de Diagnósticos de Enfermagem proposta pela NANDA (North American Nursing Diagnosis Association) ao Modelo Conceitual de Horta ${ }^{(18)}$. Com a implantação dessas propostas, durante um período de três anos, observou-se que todas as etapas do processo de enfermagem estavam sendo documentadas conforme proposto (coleta de dados, diagnóstico de enfermagem, planejamento, implementação e avaliação). Após esse período, constatou-se que os registros de enfermagem não mais evidenciavam a inter-relação entre as informações apresentadas na coleta de dados com os diagnósticos estabelecidos e, conseqüentemente, com o plano de cuidados e a avaliação. A prescrição de enfermagem continuava sendo registrada regularmente, mas isso não ocorria com as demais etapas do processo de enfermagem. Freqüentemente, os enfermeiros dessa Unidade se referiam ao processo de enfermagem como se essa metodologia representasse apenas a sua documentação.

Esses são aspectos que nos inquietam e que motivaram a realização desse estudo. Assim, para melhor compreender a situação, no que se refereàimplementação dessa metodologia de assistênciana Unidade de Queimados do HCFMRP, realizou-se estudo etnográfico com os objetivos de investigar o significado cultural que os profissionais de enfermagem, que atuam nessa Unidade, atribuíam ao processo de enfermagem e os fatores que estariam interferindo na implementação do processo de enfermagem na Unidade segundo a percepção desses profissionais.

\section{METODOLOGIA}

Para o desenvolvimento do estudo, foi necessária a obtenção do consentimento formal da Divisão de Enfermagem do HCFMRP e dos 
profissionais da Unidade de Queimados desse Hospital. Iniciado o trabalho de campo, utilizou-se para coleta de dados a observação participante e entrevistas semi-estruturadas. A princípio, as observações participantes foram conduzidas pelas seguintes questões orientadoras: o que acontece e como se comportam os auxiliares, enfermeiros e médicos em diferentes momentos de cada um dos três turnos de trabalho? Esses acontecimentos e comportamentostêmalguma relação como processo de enfermagem? Como estão organizadas as ações desses profissionais? Posteriormente, buscamos também observar os fatos descritos pelos informantes nas entrevistas. Os dados coletados através de observação participante foram registrados em um diário de campo. A partir das observações participantes, foram selecionados 14 informantes: sete enfermeiros (Enf.), cinco auxiliares de enfermagem (Aux.), um médico (Méd.) e um fisioterapeuta (Fis.), buscando encontrar, em cada categoria profissional, os diferentes tipos e os informanteschaves.

As entrevistas foram realizadas, inicialmente de modo informal, duranteas observações participantes, e registradas no diário de campo (Nc.), e a partir da escolha dos informantes, foram realizadas individualmente $e$ registradas com auxílio de gravador. Nas entrevistas, foi solicitado aos profissionais que descrevessem a forma como realizam o trabalho e, posteriormente, foram feitas outras questões, dependendo das informações recebidas, visando responder aos objetivos do estudo.

O processo de análise dos dados começou a ser realizado em conjunto com a coleta das primeiras informações. A partir daimpressão dessas informações no formato do programa de computador $O$ Ethnograph, foi realizada a análise final dos dados, mediante leitura das informações apresentadas no grupo de enfermeiros. Para análise dos dados, foram registradas nas margens ao lado do texto, as idéias que emergiam a partir da leitura das entrevistas desses profissionais. Esse processo foi orientado pela seguinte questão: o que isto melembra? Assim, foram identificados os códigos, ou seja, as unidades de significados. Posteriormente, códigos similares foram agrupados em categorias ${ }^{(19)}$. Foi realizado o mesmo procedimento com os dados coletados a partir das entrevistas realizadas com os outros grupos de profissionais e com as informações coletadas através de observações participantes. Nesse processo, não foram identificadas novas categorias que pudessem ser relacionadas com o foco deste estudo.

Os dados foram organizados em duas categorias principais que estão apresentadas em seu conjunto na Figura 1. Essa representação da categorização dos dados (Figura 1), foi sendo construída na medida em que eram identificadas as categorias e as relações entre os conceitos, e, como um mapa, orientou esse processo. Durante a análise dos dados, recorremos várias vezes aos informantes chaves para não perder, no processo de análise e construção das categorias, as perspectivas dessas pessoas.

\section{RESULTADOS}

A Unidade de Queimados possui oito leitos e atende a pacientes adultos e crianças. O quadro de pessoal compreende sete enfermeiros, quinze auxiliares de enfermagem, quatro médicos assistentes e um fisioterapeuta. Os profissionais de enfermagem são distribuídos em três turnos de trabalho, a saber, manhã, tarde e noite.

Como nos referimos anteriormente, a Figura 1, representa a categorização dos dados deste estudo, visando demonstrar a compreensão do significado cultural atribuído ao processo de enfermagem pelos profissionais que atuam nessa Unidade.

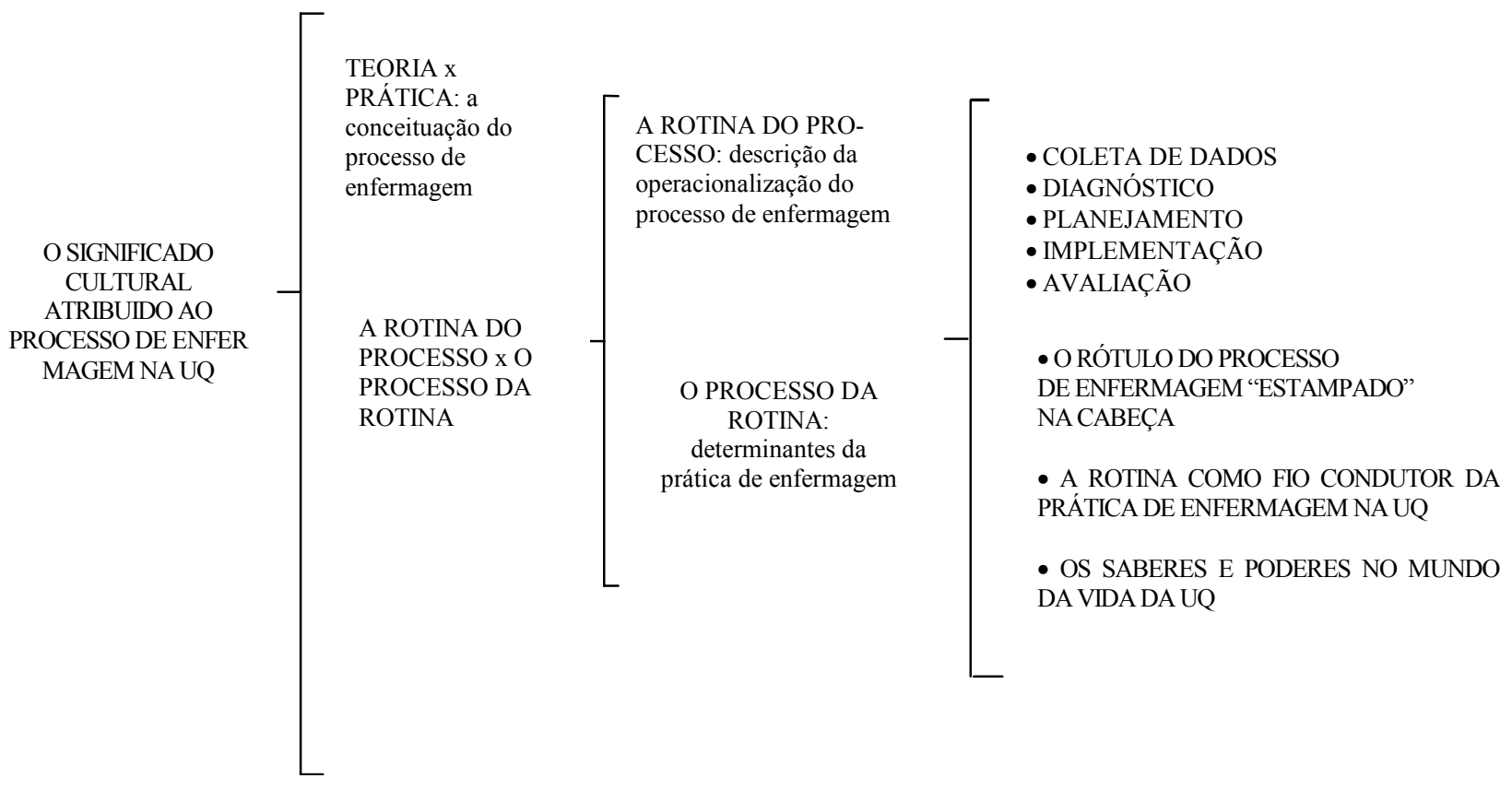

Figura 1 - Representação esquemática da categorização final dos dados 
TEORIA x PRÁTICA: a conceituação do processo de enfermagem

Na primeira categoria: TEORIA X PRÁTICA: a conceituação

do processo de enfermagem, foram agrupados os depoimentos em que os enfermeiros conceituam essa metodologia de assistência. Observa-se nos depoimentos que a realização das atividades do dia a dia é compreendida como a atividade prática, enquanto que o processo de enfermagem, considerado como uma ação de registrar, como uma atividade teórica como pode ser observado nos exemplos a seguir:

- O processo de enfermagem é ...um método... (Enf.).

- Processo de enfermagem é um conjunto de situações que ora serão feitas na prática e, outras vezes, ficam na teoria. (Enf.).

Observamos nesses exemplos e em outros depoimentos de enfermeiros eauxiliares de enfermagem, que há uma percepção do processo de enfermagem unicamente como uma atividade de documentação, eassim, essa metodologiaécompreendida como um procedimento teórico dissociado do cuidado que, por outro lado, é entendido como uma atividade essencialmente prática. Percebe-se assimuma concepçãoem que se focaliza o processo de enfermagem como uma atividade dissociada da prática e dessa forma, do próprio cuidado. Um outro aspecto apontado pelos enfermeiros, quando falam da conceituação do processo de enfermagem, é a individualização do cuidado e a visão holística do paciente, como pode ser observado nos exemplos a seguir:

- Acho que o processo de enfermagem é fazer uma prescrição individualizada para o paciente... (...) ...os enfermeiros estão ao lado do paciente fazendo a evolução do paciente como um todo, psicológica, fisica, totalmente... (Enf.).

Foi observado, nos depoimentos dos enfermeiros dessa Unidade, que eles compreendem o processo de enfermagem enquanto um método deorganização do trabalho que possibilita o cuidado individualizado. Entretanto, para eles, o processo de enfermagem é considerado como uma atividade teórica dissociada da prática.

Ocuidado centrado na pessoa ea abordagem holísticado paciente têm sido adotados por muitos modelos teóricos de enfermagem, criando uma linguagem que tem sido utilizada pelos enfermeiros e no ensino de enfermagem, mas que nem sempre fazem parte do dia a dia desses profissionais, como poderá ser observado na categoria a rotina do processo: descrição da operacionalização do processo de enfermagem descritaa seguir.

A rotina do processo: descrição da operacionalização do processo de enfermagem

Nessa categoria, foram reunidos os depoimentos em que é abordada a forma como o processo de enfermagem tem sido interpretado $\mathrm{e}$ efetivamente operacionalizado na prática. A proposta inicial, elaborada pelos próprios enfermeiros, era de que o processo de enfermagem deveria ser implementado considerando as seguintes etapas: coletade dados, diagnóstico de enfermagem, planejamento, implementação e avaliação. Embora os enfermeiros se reportem a todas essas etapas, foi observado na Unidade e também relatado nos depoimentos de enfermeiros eauxiliaresquea prescrição deenfermagemé registrada regularmente, oquenão acontece comas demais etapas.

-...o enfermeiro faz sempre a prescrição... (...) a prescrição tem que ser feita... é uma tarefa que você tem que fazer... (Enf.).

- ... a coleta de dados e o diagnóstico ficam sem fazer, mas a prescrição nunca ficou. (Enf.).

Considerando esses exemplos e outros depoimentos, uma questão a ser respondidaé se a prescrição de enfermagem resulta da efetiva realização das outras etapas raramente registradas. Na percepção de alguns enfermeiros, o processo de enfermagem já estaria incorporado no trabalho, mas com falhas relacionadas principalmente ao seu registro. Entretanto, no depoimento do enfermeiro a seguir, observa-se uma outra visão:

- Quando eu faço a prescrição, a coleta de dados, é como se eu estivesse me enganando! Eufaço maséfachada, porque não existe... Nãoéque não existe porque eu não acredito, entendeu? Eu acho que não existe porque é falso... (Enf.).

Observamos que a elaboração diária das prescrições de enfermagem, nessa Unidade, não está vinculada a uma avaliação anterior do paciente e que essa é uma das razões que leva os auxiliares de enfermagem a não consultarem a prescrição de enfermagem. Essa situação é reportada pelos auxiliares de enfermagem no exemplo a seguir:

- ... o pessoal notou isso: ...não viu o paciente, mas veio e prescreveu... (Aux.).

Os diagnósticos de enfermagem, quando estabelecidos, não são utilizados para a fundamentação da prescrição de enfermagem, como pode ser observado na resposta desse enfermeiro:

- Você já usou o diagnóstico para fazer a prescrição? (Pesquisador).

- Não, mas deveria usar... (Enf.).

Por outro lado, o enfermeiro muitas vezes avalia o paciente e determina as ações a serem realizadas, mas estas não são registradas:

Nc.: Um enfermeiro foi chamado por um auxiliar que queria saber como seria feito 0 curativo de uma paciente: aberto ou fechado? Ele avaliou o paciente e conversou com ele sobre as formas como o procedimento poderia ser realizado e propôs que o curativo fosse deixado aberto, discutiu com o paciente as conseqüências que isso poderia ter para ele e concordaram que o melhor seria deixá-lo aberto..

Nessa ação, observa-se que foi buscado um acordo com as pessoas envolvidas. Em um outro tipo de situação, o enfermeiro, diante de um problema procura resolver a situação, mas não leva em conta as outras pessoas envolvidas, ou seja, não avalia o paciente.

- ...por exemplo dor, sempre que o auxiliar chega para você e diz: "o paciente está com muita dor," eu pego a papeleta e vejo se tem prescrição para dor, se ele pode ser medicado, qual é a medicação melhor naquele momento... (Enf.).

Assim, observamos que, no seu dia a dia, o enfermeiro toma decisões em que, algumas vezes, considera as pessoas envolvidas e outras não. A realização diária da prescrição de enfermagem foi incorporada no quotidiano dos enfermeiros dessa Unidade, mas como uma atividade burocrática. As outras etapas, com as quais a prescrição de enfermagem 
deveria manter uma relação de interdependência, não fazem parte desse quotidiano, embora tenham sido enumeradas pelos enfermeiros. É possivel que as razões paraa situação, aqui descrita, estejam nos fatores que interferem na prática do processo de enfermagem nessa Unidade, segundo os profissionais que nela trabalham: o ensino dessa metodologia de assistência, que estabelece um rótulo do processo de enfermagem estampado na cabeça, a rotina como o fio condutordo trabalho de enfermagem, os saberes e poderes no mundo da vida da Unidade de Queimados.

Fatores que interferem na prática do processo de enfermagemnessa Unidade

O rótulo do processo de enfermagem, estampado na cabeça dos profissionais de enfermagem, que atuamnessa Unidade, éo de umaatividade burocrática, desempenhada como mais uma tarefa, que tem como expressão principal a prescrição de enfermagem. Esse é um dos fatores que interferem na operacionalização dessa metodologia.

No ensino do processo de enfermagem, tem-se enfatizado as etapas de coleta de dados, diagnóstico e planejamento. Desse modo, muitas vezes, as ações são planejadas, mas os alunos não chegam a implementálas e, conseqüentemente, não podem avaliar o resultado, como observamos no depoimento a seguir:

- Na Escola, a gente pegava um paciente e via todos os problemas, e quando ia implementar, acabava o estágio... (Enf.).

0 ensino do processo de enfermagem, muitas vezes, não considera a realidade social em que essa metodologia de assistência é implementada, edesse modo, como afirma o enfermeiro, a seguir, estabelecese o rótulo do processo de enfermagem estampado na cabeça...

- Ele (Enf.) tem o rótulo do processo de enfermagem estampado na cabeça, como ele aprendeu na Escola, vê apenas como uma parte escrita, e não é o escrito que vai importar, mas sim a atitude. (Enf.).

Nos depoimentos em que abordam a operacionalização do processo de enfermagem, os enfermeiros focalizam a questão da documentação, como seessametodologia de assistência se resumisse nessa atividade. Nesse contexto, o que importa é a realização do registro e, como foi afirmado anteriormente, a prescrição de enfermagem é registrada diariamente, mas nem sempre resulta de uma avaliação do paciente. Assim, a forma como o processo de enfermagem tem sido interpretado e operacionalizado nessa Unidade, a ênfase que tem sido dada à sua documentação em detrimento do foco do processo de enfermagem que deveria ser o paciente, resulta num plano de cuidados que não reflete uma assistência individualizada ao paciente. 0 significado cultural que os profissionais de enfermagem dessa Unidade atribuem ao processo de enfermagem é o de uma atividade burocrática.

Nos relatos dos profissionais de enfermagem foi possível observar que o fio condutor do trabalho de enfermagem é a rotina, que se diferencia em alguns aspectos, dependendo do turno de trabalho. Esse é um outro fator que interfere na implementação dessa metodologia de assistência:
- Acho que o que direciona o trabalho deles (pessoal auxiliar) são as rotinas mesmo... eles já criaram na cabeça deles... (...) ...é uma rotina, um rotinão. (Enf.).

Um dos problemas da condução da prática unicamente através das rotinas é, então, o risco de automação, como afirma o auxiliar de enfermagem a seguir:

- Isso aí (cuidado prescrito) é feito automático... (Aux.).

Nesse contexto, em que se valoriza o cumprimento da rotina, é importante que 0 enfermeiro passe um plantão organizado para 0 outro enfermeiro que irá entrar no turno seguinte:

-...mas o básico mesmo eles fazem direitinho, o pessoal faz, a gente da equipe faz, o enfermeiro até sabe onde vai falhar, então ele intervém, ele sabe que a maioria do pessoal esquece alguns detalhes, não dá muito valor para alguns, então, ele vai lá e arremata, ele termina o serviço... (Enf.).

Portanto, diante das atividades não realizadas, o enfermeiro vai lá e arremata, ou seja, faz o acabamento da rotina que ficou para trás. Nesse contexto, o que importa é o cumprimento das ações, e assim, é atribuído maior valor aos enfermeiros que executam o cuidado ao paciente, isto é, que ajudam a finalizar o trabalho que tem que ser cumprido:

- O bom enfermeiro é aquele que vai lá e dá cuidados. (Enf.).

A Instituição, enquanto uma organização burocrática, não espera a realização de outro cuidado além daquele que já está estabelecido pelo médico, pelo especialista que detém o poder de decidir, como pode ser observado a partir dos dados agrupados nessa categoria: os saberes e poderes no mundo da vida da Unidade de Queimados. Esse é outro fator que interfere na prática do processo de enfermagem.

- Eles (Instituição) acham que a enfermagem é isso, é ser tipo só complementação médica, então, enquanto o médico não reclama, a enfermagem está ótima... (Enf.).

O médico também considera a prescrição de enfermagem como cuidados básicos que eles esquecem de prescrever:

- O que você acha da Prescrição de Enfermagem? Você já reparou, já leu? (Pesquisador)

- ...são os cuidados aí básicos de enfermagem mesmo, que a gente acaba esquecendo se você tem bastante trabalho, às vezes, passa isso. (Med.).

Foi observada uma situação em que o fisioterapeuta solicita ao enfermeiro que realize a prescrição de um cuidado:

- Precisa prescrever para colocar a tala no braço do Antônio à noite. (Fis. 1). - Tá bom. (Enf.).

Para os enfermeiros, os auxiliares de enfermagem não sentem a necessidade da prescrição de enfermagem porque entendem que já sabem o que devem fazer. Essa percepção é também confirmada por alguns auxiliares:

-...primeiro que o pessoal acha: "eu estou aqui há tanto tempo, eu seio meu serviço..." (Aux.).

Durante a internação, com o passar do tempo, o paciente passaa conhecer as competências de cada um e, pelo menos em parte, passa a entender o horizonte que fundamenta as decisões no contexto desta Unidade, reivindicando a sua participação. Entretanto, ao paciente, freqüentemente, é 
oferecida pouca,ou nenhuma oportunidade de participação no próprio cuidado.

O exemplo a seguir ilustra essa situação:

Nc: Uma auxiliar de enfermagem me contou que um paciente com grande extensão de área queimada solicitava medicações para alivio da dor a cada seis horas, porque percebeu que era essa a dosagem permitida, e de seu quarto controlava o tempo, poiso relógio do posto de enfermagemera visto de sua cama. Aauxiliarde enfermagem conclui:

-...imagine que tivemos que mudar o relógio de lugar! (Aux.).

Assim, de alguma forma, todos exercem algum tipo de poder. A posição mais baixa na escala hierárquica dessa organização burocrática, em que todos possuem algum tipo de saber e exercem ou tentam exercer 0 poder, parece ser a do paciente. Nesse contexto, o relógio é retirado da parede para que o paciente, tentando controlar ele mesmo o momento de aliviar a dor, não interfira na organização do trabalho. Nesse tipo de ação, há pouco espaço para interações; o modo de fazer já está determinado, importando finalizar o trabalho.

\section{O SIGNIFICADO CULTURAL DO PROCESSO DE ENFERMAGEM NA UNIDADE DE QUEIMADOS}

No processo de interpretação dos dados utilizamos a Teoria da Ação Comunicativa de Jürgen Habermas ${ }^{(20)}$, por entender queessa orientação possibilitaria compreender os significados culturais atribuídos ao processo de enfermagem, considerando o contexto em que ele é implementado e também possibilitaria uma reflexão crítica sobre as concepções a respeito dessa metodologia de assistência.

Nesta teoria, o autor estabelece uma classificação de ações em que a ação teleológica refere-se à realização de fins definidos, sob determinadas condições e pode ter uma dimensão instrumental ou estratégica. Uma ação instrumental está voltada para realização de tarefas técnicas de controle da natureza e dos estados de coisas que fazem parte do mundo objetivo. Na ação estratégica, os atores tentam alcançar os objetivos de sua ação influindo externamente sobre a definição da situação, as decisões ou motivos de seu adversário ${ }^{(20)}$. A ação comunicativa ocorre quando duas ou mais pessoas procuram claramente chegar a um entendimento voluntário de modo a poder cooperar. Paratanto, énecessário queos envolvidos estejam dispostos a permitir que a validade de suas afirmações possa ser criticada ou anulada por outros agentes ${ }^{(20)}$. Distintamente da ação estratégica, nesse tipo de ação, os atores "tratam de harmonizar internamente seus planos de ação, de só perseguir suas respectivas metas sob condição de um acordo existente ou a ser negociado sobre a situação e as conseqüências esperadas ${ }^{\prime \prime 20)}$. 0 processo de entendimento mútuo depende da aprovação racional do conteúdo de uma asserção e sempre se fundamenta em crenças comuns.

Considerando essa perspectiva, enquanto método de organização do trabalho, o processo de enfermagem caracteriza-se como uma ação estratégica, um meio que orienta a realização dos cuidados de enfermagem como baseemescolhas racionais. Entretanto,como afirmamos anteriormente, além do método, passos definidos para o alcance de um fim específico, entendemos que o processo de enfermagem pressupõe o cuidado centrado na pessoa. Nesse sentido, o paciente e seus familiares devem ser envolvidos na implementação de todas as etapas dessa metodologia, refletindo o cuidado centrado na pessoa, a partir de uma ação em que o entendimento é fundamental.

Entretanto, o significado cultural que os enfermeiros dessa Unidade de Queimados atribuem ao processo de enfermagem é o de uma atividade burocrática que, implementada dessa forma, o afasta mais do que aproxima do cuidado do paciente. Nesse sentido, a prática do processo de enfermagem, nessa Unidade, revela-se como uma atividade mecânica. Essa situação é também identificada pelos auxiliares de enfermagem, quando focalizam a prescrição de enfermagem como um lembrete, uma lista de atividades de rotina que eles já conhecem. Assim, embora a prescrição de enfermagem seja realizada diariamente, ela não se baseia em uma avaliação do paciente, não retratando a sua individualidade. Os cuidados, sejam eles prescritos ou não, são implementados rotineiramente.

Assim, o processo de enfermagem, para esses profissionais, caracteriza-se como uma rotina, implementado num contexto onde o espaço para as interações é limitado pela necessidade do cumprimento das tarefas. Determinando a rotina do processo estão: o ensino dessa metodologia de assistência que estabelece um rótulo do processo de enfermagem estampado na cabeça, a rotina como o fio condutor do trabalho de enfermagem, os saberes e poderes no mundo da vida da Unidade de Queimados.

$\mathrm{Na}$ Unidade em estudo, como se pôde verificar, a coordenação das ações, muitas vezes, é guiada por processos não comunicativos, pela tradição, pelos valores instrumentais e pelo poder, importando, nesse caso, a finalização da ação, da tarefa. Isso foi observado na forma como as ações são realizadas, e nas próprias prescrições de enfermagem que incorporam as tarefas de caráter rotineiro. Assim, a prática de enfermagem nessa Unidade é orientada pela ideologia da rotina. Considerou-se o conceito de ideologia como um conjunto de crenças eatitudes adotadas como certas, que orientam a interpretação da realidade de um grupo de pessoase, desse modo, dirigem as suas vidas ${ }^{(21)}$.

No quotidiano da prática de enfermagem nessa Unidade, as rotinas foram incorporadas como um guia para a realização das ações, e o poder atribuído ao médico pela Instituição não é questionado; da mesma forma, o poder atribuído aos profissionais não é questionado pelo paciente, que se submete à rotina hospitalar. Assim, prevalece o que está estabelecido $\mathrm{e}$, operando no contexto das leis, a administração é guiada por critérios próprios de racionalidade. Nessa perspectiva, percebe-se que o exercício do poder não considera a razão prática do uso das normas - o cuidado ao paciente - mas sim, a efetividade no cumprimento de um programa estabelecido ${ }^{(20)}$.

Essasituação mostraa colonização do mundo da vida das pessoas que convivemnessa Unidade. Omundo da vidaéentendido como um sistema de referências que fundamenta as decisões, que permite a interpretação dos componentes internos de uma ação, transmitidos através da cultura e da 
linguagem. O mundo da vida articula os processos de interação social e de socialização dos indivíduos, constituindo-se de cultura, sociedade e personalidade. A cultura é o acervo de saberes que fundamenta as interpretações dos atores quando buscam um acordo sobre algo no mundo; a personalidade refere-se às competências que capacitam um sujeito para falar e agir e a sociedade é composta pelo conjunto de normatizações legitimadas que orientam as relações dos participantes em um grupo social ${ }^{(20)}$.

O mundo da vida é ameaçado pela interferência da ação instrumental, que estabelece uma ligação deste com o sistema, passando a ocorrer a colonização do mundo da vida que se caracteriza pelo predomínio da racionalidade técnica e da ação instrumental, levando ao aparecimento das patologias do mundo da vida ${ }^{(20)}$. Segundo esse autor, quando deveriam ser valorizados os processos comunicativos, pois as ações são realizadas com pessoas, passa a haver um processo de coisificação. Esse processo de coisificaçãoé marcado por algumas características que passama fazer parte do estilo de vida das pessoas, a saber, o individualismo, a especialização do sabere, conseqüentemente, a tecnificação de questões práticas, viabilizadas no contexto hospitalar pela administração burocrática ${ }^{(20)}$.

O contexto hospitalar, em que os enfermeiros têm tentado desenvolver o processo de enfermagem, tem se caracterizado pela ideologia de dominação da medicina e pelas estruturas de poder da Instituição que reforçam o poder do médico, e mais recentemente, dos administradores ${ }^{(8)} .0$ médico tem como seus aliados todos os ingredientes do poder: a ideologia e a tecnologia. A enfermagem tem se caracterizado por ocupar uma posição de subordinação na Instituição que, na maioria das vezes, adota uma forma de organização burocrática, valorizando a especialização e o controle, e favorecendo a manutenção do foco de atenção da enfermagem na execução das tarefas, e não no atendimento da pessoa ${ }^{(8)}$.

No ensino e na implementação, pelos enfermeiros, dessa metodologia de assistência, não tem sido considerado o contexto da Instituição onde ela é implementada. Sob esse aspecto, em um estudo em que foi analisada a linguagem utilizada nos livros textos norte-americanos, quando abordam 0 assunto processo de enfermagem, a autora concluiu que a linguagem utilizada nesses livros apresenta essa metodologia de assistência como uma abordagem dissociada do contexto na qual é implementada, dissuadindo o enfermeiro de questionar a realidade social e os fatores políticos

\section{REFERÊNCIAS BIBLIOGRÁFICAS}

1. Lei do exercício profissional da enfermagem de 1986; Pub. L. nº 7498 (Jul. 26, 1986).

2. Barros ALBL. O trabalho docente assistencial de enfermagem no Hospital São Paulo da UNIFESP/EPM. [tese]. São Paulo (SP): Escola Paulista de Medicina/UNIFESP; 1998.

3. Campedelli MC, Gaidizinski RR. Ametodologiaassistencial de enfermagem na prática - Hospital Universitário da USP. Rev Esc Enfermagem USP 1987; 21(n.especial):62-7. e sociais envolvidos na situação do cuidado. Nessa perspectiva, o processo de enfermagem assume características de uma ação instrumental e está associado a um interesse técnico de controle, que não permite a focalização apropriada de questões práticas, inerentes ao cuidado de enfermagem, uma vez que o principal objetivo desse interesse é o controle e a previsibilidade ${ }^{(22)}$.

Entretanto, quando parece não existir mais lugar para processos comunicativos, foi também possivel perceber que, no quotidiano da prática de enfermagem dessa Unidade de Queimados, em que as pessoas se relacionam e utilizam o potencial criativo para o trabalho, também ocorrem ações comunicativas. São detalhes do cuidado, em que se observa um entendimento com o paciente e com o restante da equipe, cujos resultados parecem mais efetivos e eficazes. Nesse caso, o paciente é considerado e pode participar ativamente pois, com o tempo de internação, passaa conhecer o pano de fundo no qual as decisões são fundamentadas.

Por meio daação comunicativa, pode-se romper a cadeia daação instrumental, mantendo a rotina dentro dos limites em que ela se faz necessária ${ }^{(23)}$. Desse modo, é possível romper com a ideologia da rotina, em busca da utopia de um cuidado individualizado. O termo utopiaé empregado, neste estudo, com o sentido de uma meta a ser alcançada. Por meio da práxis comunicativa quotidiana e do discurso, poderiam ser criadas condições para que os próprios participantes começassem a construir livremente o seu destino, pretendendo uma intersubjetividade livre, fundamentada numa comunicação que não seja nem impedida pela força, nem descaracterizada pelas ideologias ${ }^{(20)}$. Para que isso possa ocorrer, é importante que sejam propiciados momentos informais de discussão entre os membros da equipe de enfermagem que atuamnessa Unidade, que teriam como objetivo estimular uma reflexão sobre os valores éticos e morais que envolvem o cuidado do paciente, e sobre o significado atribuído ao processo de enfermagem, pelos profissionais enfermagem.

Nesse aspecto, o processo de enfermagem poderia ser implementado como uma metodologia de assistência que orientaria a organização do cuidado necessário, a partir de um acordo entre a equipe e o paciente. $O$ registro do processo de enfermagem é importante, mas a interpretação dessa metodologia de assistência de forma rígida valorizando unicamente a sua documentação, "éumaameaçaa liberdade dos enfermeiros que eles deveriam resistir a todo custo"(8).

4. Cruz DALM, Ribeiro FG, Dutra VO, Caracciolo LT. Sistematização da assistência de enfermagem em uma área de recuperação da saúde. Rev Esc Enfermagem USP 1987; 21 ( $n^{\circ}$ especial): 68-76.

5. Lagana MT, Araujo TL, Silva SH, Santos LC. Metodologia assistencial de enfermagem: reflexos baseados em experiência de ensino. Rev Esc Enfermagem USP 1987; 21 ( $\mathrm{n}^{0}$ especial):21-8.

6. Fernandes M. O processo de enfermagem: aplicação em uma unidade de hospital escola do interior. Rev. Rev Esc Enfermagem USP 1987; 21 ( $n^{\circ}$ especial):88-99. 
7. Kenney JW. Relevance of theoretical approaches in nursing practice. In: Christensen J, Kenney JW Nursing process: application of theories, frameworks, and models. 3. ed. St. Louis: Mosby; 1990. p.3-18.

8. Ford P, Walsh M. New rituals for old: nursing through the looking glass. $2^{\text {nd }}$ ed. London: Butterworth Heinemann; 1995.

9. Milne $D$. The more things change the more they stay the same': factors affecting the implementation of the nursing process. JAdv Nurs 1985; 10(1):3945.

10. De LaCuestaC. The nursing process from developmentto implementation. J Adv Nurs 1983; 8(1):65-7.

11. Henderson V Nursing Process: a critique. Holistic Nurs Pract 1987; 1(3):718.

12. Howse $E$, Bailey J. Resistance to documentation: a nursing research issue. J Nurs Stud 1992; 29(4):371-80.

13. Walters KR, Easton N. Individualized care: is it possible to plan and carry out? J Adv Nurs 1999; 29(1):79-87.

14. CruzDALM. Diagnósticos de enfermageme padrões funcionais de saúde alterados em pacientes por cardiologia chagásica crônica. [dissertação]. São Paulo (SP): Escola de Enfermagem/USP;1989.

15. Maria VLR. Preparo de enfermeiras para a utilização de diagnósticos de enfermagem: relato de experiência. São Paulo. [dissertação]. São Paulo(SP): Escola de Enfermagem/USP; 1990.
16. Jesus CAC. Raciocínio clínico de graduandos e enfermeiros na construção de diagnósticos de enfermagem. [tese]. Ribeirão Preto (SP): Escola de Enfermagem de Ribeirão Preto/USP; 2000.

17. Rossi LA O processo de enfermagem em uma unidade de queimados: análise e reformulação fundamentadas na pedagogia da problematização. [tese]. Ribeirão Preto (SP): Escola de Enfermagem de Ribeirão Preto/USP; 1992.

18. Rossi LA, Dalri MCB. Processo de enfermagem numa Unidade de Queimados: análise e proposta de reformulação segundo o modelo conceitual de Horta e a Taxionomia I dos Diagnósticos de Enfermagem da NANDA Rev Esc Enfermagem USP 1993; 27:328-54.

19. Hammersley M, Atkinson P. Ethnography: principles in practice. $7^{\text {th }}$ ed. London: Routledge; 1992.

20. Habermas J. The theory of communicative action. Reason and the rationalisation of society. Boston: Beacon Press; 1984.

21. Mezirow J. A critical theory of learning and education Adult Educ 1981; 32(1):3-23.

22. Hiraki A. Tradition, rationality and power in introductory nursing textbooks: a critical hermeneutics study. ANS 1992;14(3):1-12.

23. Freitag B. A teoria critica: ontem e hoje. 5. ed. São Paulo: Brasiliense; 1994. 